\title{
Evaluation of Morbidity and Mortality in Eclampsia: A Study in a Tertiary Care Hospital, Rajshahi, Bangladesh
}

\author{
Dr. Nahid Sultana ${ }^{1 *}$, Dr. Md. Zulfiqur $\mathrm{Ali}^{2}$, Dr. Shakina Khatun ${ }^{3}$
}

\author{
${ }^{1}$ Assistant Professor, Department of Gynaecology \& Obstetrics, Rajshahi Medical College Hospital, Rajshahi, Bangladesh \\ ${ }^{2}$ Assistant Professor, Department of Orthopaedic Surgery, Shaheed Mansur Ali Medical College, Sirajganj, Bangladesh \\ ${ }^{3}$ Assistant Professor, Department of Gynaecology \&Obstetrics, Shaheed M. Mansur Ali Medical Hospital, Sirajgonj, Bangladesh
}

DOI: $10.36347 /$ sjams.2020.v08i08.002

| Received: 26.07.2020 | Accepted: 03.08.2020 | Published: 05.08.2020

*Corresponding author: Dr. Nahid Sultana

Abstract

Original Research Article

Introduction: Eclampsia is a hypothetically life-threatening rare tricky situation of the hypertensive disorders of pregnancy, which is responsible for huge records in morbidity and deaths among women of reproductive age and their offspring. It is an occurrence of convulsion linked with pregnancy complicated by preeclampsia. The estimate of incidence and the burden of eclampsia is still a challenging pursuit worldwide; currently only seven countries have national data on the topic. Aim of the study: To assess the morbidity and mortality in eclampsia. Methods: This was a cross sectional observational study carried out in the Department of Obstetrics and Gynaecology in 250 Bedded General Hospital, Pabna, Bangladesh during the period from June 2016 and July 2016. Proper written consent form all the participants were obtained and the ethical committee of the hospital had approved the study before starting the intervention. In total 178 pregnant women with eclampsia were finalized as the study population. Result: In our study we found in total 148 live births from total 178 mothers which were $83.15 \%$ against total study population. Among all the babies 139 were survived which was $93.91 \%$ among total live births. Death after birth was 9 in number which was $6.08 \%$ among total live births. Early neonatal death was 13 in number which was $7.3 \%$ against total mothers. Stillbirths were 16 in number which was $9 \%$ against total mothers. In perinatal complication analysis we found 42 babies with jaundice which was $28.38 \%$ among live births. Babies with septicemia were 28 (18.92\%), with respiratory distress 25 (16.89\%), with neonatal convulsion were 7(4.73\%) and with no complication were 46 (31.08\%). Conclusion: It was observed in our study that; lower income families have a worse performance in all obstetric health care indicators among women with eclampsia. So, Proper health care and mental health facilities in order to get better obstetric and perinatal outcomes might be the faster route to reduce severe maternal outcome due to eclampsia.

Keywords: Eclampsia, Pregnancy, Reproductive Age, Severe Maternal Outcome.

Copyright @ 2020: This is an open-access article distributed under the terms of the Creative Commons Attribution license which permits unrestricted use, distribution, and reproduction in any medium for non-commercial use (NonCommercial, or CC-BY-NC) provided the original author and source are credited.

\section{INTRODUCTION}

Eclampsia is a hypothetically life-threatening rare tricky situation of the hypertensive disorders of pregnancy, which is responsible for huge records in morbidity and deaths among women of reproductive age and their offspring [1-4]. It is an occurrence of convulsion linked with pregnancy complicated by preeclampsia [5]. The estimate of incidence and the burden of eclampsia is still a challenging pursuit worldwide; currently only seven countries have national data on the topic [6]. A study on preeclampsia and eclampsia, performed in 2013, specified that the prevalence of eclampsia varies from up to $4 \%$ in Nigeria and 0 to $0.1 \%$ in Europe; Brazilian studies showed a $0.6 \%$ incidence $[6,7]$. However, $94.6 \%$ of the data were collected in the USA, emphasizing a noticeable regionalization bias and, thus, the need for more studies, particularly in low- and middle-income countries [6]. The incidence of eclampsia in developed countries is estimated to about 5-7/10,000 deliveries. Whereas in developing nations varies widely 1 case per 100 to 1 case per 1700 pregnancies [8]. Existing research and data reports that globally ten million women develops pre-eclampsia each year; of which 76,000 women die from this condition. Most of these deaths occur in Low and Middle Income Countries (LMICs) [9]. Preeclampsia precursor to eclampsia ranges between $2 \%$ to $10 \%$ of total pregnancies globally. WHO estimates frequency of preeclampsia is seven times complex in developing countries than developed world [2]. Eclampsia has always been as a major public health issue both in developed and developing countries. Still, owing to limited number of facilities-based service provision, accessibility, and affordability of patients a very few studies were done 
considering fetal and maternal outcome of eclampsia in Bangladesh. Bearing in mind the scarce quantity of evidence, we carried out this study in an attempt to assess the morbidity and mortality in eclampsia. This study will offer new information that will help to policy planers, to formulate strategies to improve perinatal outcome in eclampsia and will create some interest for further research.

\section{OBJECTIVES}

\section{a) General objective}

- To assess the morbidly and mortality which are related to eclampsia in Bangladesh

\section{b) Specific Objectives}

- To assess the prevalence of perinatal death related to eclampsia in Bangladesh

- To assess the risk factors of eclampsia in women in Bangladesh

\section{METHODOLOGY \& MATERIALS}

This was a cross sectional observational study carried out in the Department of Obstetrics and Gynaecology in 250 Bedded General Hospital, Pabna, Bangladesh during the period from June 2016 and July 2016. Proper written consent form all the participants were obtained and the ethical committee of the hospital had approved the study before starting the intervention. In total 178 pregnant women with eclampsia were finalized as the study population. Eclampsia patients admitted to this hospital during the study period constitute the samples. After admission, diagnosis was made mostly on the basis of history and clinical presentation with minimum aids. We used Face to face interview, examination finding \& investigation report, Semi structured questionnaire \& check list. Through proper administrative procedure by the researcher took the verbal consent of the patient to interview and examine her. Finding was recorded after data collection, data were checked for consistency and necessary corrections were made of needed. Data were collected and analyzed by using MS-Excel and SPSS version 20 . According to the exclusion criteria, patients who were discharged within 48 hours of delivery and cases other than clinically confirmed eclampsia were excluded from the study.

\section{RESULT}

In our study among all the participants we found most of the cases were from 20 to 30 years age group. The number was 120 which were $67.42 \%$ of total population. This trend was followed by $37(20.79 \%)$ from $>30$ years' age group and $21(11.80 \%)$ from $<20$ years' age group. In socio-economic status analysis we found the highest cases from lower class people which $47.75 \%(\mathrm{n}=85)$. This trend was followed by 59 (33.15) from middle class and $34(19.10 \%)$ from higher class families. Most of the cases of our study were with 1-2 parity and their number was $95(53.37 \%)$. It was followed by $69(38.76 \%)$ with no parity and $14(7.87 \%)$ with three or more parity. In our study we found most of the patients taken irregular antenatal care. The number of such type of cases was $98(55.06 \%)$. This trend was followed by $49(27.53 \%)$ had not taken antenatal care at all and only $31(17.42 \%)$ patients taken proper antenatal care. As per the report of gestation period we found $95(53.37 \%)$ were with gestation of 2936 weeks which was the highest. This trend was followed by $71(39.89 \%)$ were with $>37$ weeks and 12 $(6.74 \%)$ were with $<28$ weeks. In our study we found in total 148 live births from total 178 mothers which were $83.15 \%$ against total study population. Among all the babies 139 were survived which was $93.91 \%$ among total live births. Death after birth was 9 in number which was $6.08 \%$ among total live births. Early neonatal death was 13 in number which was $7.3 \%$ against total mothers. Stillbirths were 16 in number which was $9 \%$ against total mothers. In perinatal complication analysis we found 42 babies with jaundice which was $28.38 \%$ among live births. Babies with septicemia were $28(18.92 \%)$, with respiratory distress $25(16.89 \%)$, with neonatal convulsion were 7 (4.73\%) and with no complication were 46 (31.08\%).

Table-I: Age distribution of participants $(\mathrm{N}=178)$

\begin{tabular}{|c|c|c|}
\hline Age (Years) & $\mathbf{n}$ & $\boldsymbol{\%}$ \\
\hline$<20$ & 21 & 11.80 \\
\hline $20-30$ & 120 & 67.42 \\
\hline$>30$ & 37 & 20.79 \\
\hline
\end{tabular}

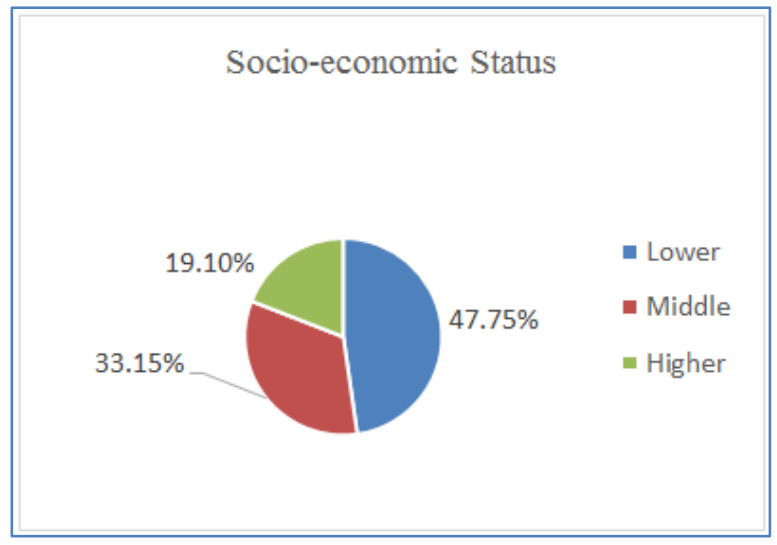

Fig-I: Distribution of socio-economic status of participants $(\mathrm{N}=178)$

Table-II: Distribution of parity of participants $(\mathrm{N}=\mathbf{1 7 8})$

\begin{tabular}{|c|c|c|}
\hline Parity & $\mathbf{n}$ & $\mathbf{\%}$ \\
\hline 0 & 69 & 38.76 \\
\hline $1-2$ & 95 & 53.37 \\
\hline$\geq 3$ & 14 & 7.87 \\
\hline
\end{tabular}

Table-III: Status of antenatal care of participants (N=178)

\begin{tabular}{|c|c|c|}
\hline Antenatal care & $\mathbf{n}$ & \% \\
\hline None & 49 & 27.53 \\
\hline Irregular & 98 & 55.06 \\
\hline Regular & 31 & 17.42 \\
\hline
\end{tabular}


Table-IV: Duration of gestation among participants $(\mathrm{N}=178)$

\begin{tabular}{|c|c|c|}
\hline Duration (Week) & $\mathbf{n}$ & $\mathbf{\%}$ \\
\hline$<28$ & 12 & 6.74 \\
\hline $29-36$ & 95 & 53.37 \\
\hline$>37$ & 71 & 39.89 \\
\hline
\end{tabular}

Table-V: Outcome of pregnancies among the study participants

\begin{tabular}{|l|c|c|}
\hline Parameters & n & \% \\
\hline Live birth & 148 & 83.15 \\
\hline Survived & 139 & 93.91 \\
\hline Death after birth & 9 & 6.08 \\
\hline Early neonatal death (END) & 13 & 7.30 \\
\hline Stillbirth ( SB) & 16 & 8.99 \\
\hline Macerated & 3 & 1.69 \\
\hline Perinatal death (END + SB) & 29 & 16.29 \\
\hline
\end{tabular}

Table-VI: Distribution of perinatal conditions/complication among live birth $(n=148)$

\begin{tabular}{|l|c|c|}
\hline Complications & n & \% \\
\hline Jaundice & 42 & 28.38 \\
\hline Septicemia & 28 & 18.92 \\
\hline Respiratory distress & 25 & 16.89 \\
\hline Neonatal convulsion & 7 & 4.73 \\
\hline No complication & 46 & 31.08 \\
\hline
\end{tabular}

\section{DISCUSSION}

Frequency of eclampsia in the hospitals of developing country is more common than the other part of the world. The occurrence of Eclampsia in Eastern India is $3.2 \%$. In Kerla is $3.8 \%, 4.9 \%$ in Andra Pradesh, $15 \%$ in Madya Pradesh and $20.7 \%$ in Bihar [10]. These statistics are greater parallel to developed countries. In a study it was stated that, 'the incidence of 1 in 3250 pregnancies in US [11] and 1 in 2000 pregnancy in Europe[12] were found. The incidence of eclampsia in developed countries is considerably low. In our study, majority of the cases $(88 \%)$ were un-booked cases and/or irregular Antenatal care, and with low socio economic status. The signs and symptoms of preeclampsia were not detected until development of eclampsia was observed. In our study eclampsia was common in young pregnant woman same as in the (83\%) study of Chaurvedi et al. [13]. Concerning parity, our study shows eclampsia was meaningfully linked to primigravida $(53.37 \%)$ and this finding is constant with finding of Acharya G et al. (71.42\%) this may explain the immunological causes for preeclampsia and eclampsia and PND is the highest in this group. In relation to perinatal outcome, it shows that $83.15 \%$ was born alive and total still birth in eclamptic patients were 9\% which are similar to study formerly done in Bangladesh. The hypertensive disorders throughout pregnancy are significant sources of maternal death all over the world and most of these deaths are recognized to eclampsia. The hypertensive syndromes also subsidize widely to still birth and neonatal morbidity and death. In our study, perinatal death was $16.29 \%$ which is inferior to that of study done by chowdhury $\mathrm{P}$ where the rate was $20 \%$ Patan hospital $31.25 \%, 38.6 \%$. We also showed that $31.08 \%$ babies out of 148 live birth had no complication and $28.38 \%$ developed neonatal jaundice, $18.92 \%$ had developed septicemia, $16.89 \%$ had respiratory distress and $4.73 \%$ suffered from neonatal convulsion. These statistics is similar to many studies done in Bangladesh, earlier. Hypertensive expectant mothers (or gravidas) are predisposed to the improvement of potentially fatal complications of pregnancy particularly abruption placentae, distributed intravascular coagulation cerebral haemorrhage hepatic miscarriage and acute renal failure. Perinatal death was very high in our study compared to Baha's [9] study $(11.8 \%)$. But in Bangladesh in several studies perinatal death was $32.1 \% 7,28 \% 8$ and $26.8 \%$ [14]. In a review of four different studies presented at the First International Conference of Obstetrics and Gynecology held in Bangladesh, perinatal mortality in eclampsia various from (31 to 41) \% [16], and it seemed very high in contrast to general perinatal mortality rate in Bangladesh which at present is 70 per thousand livebirths [17]. In developed country, perinatal mortality in pre-eclampsia diverse from 35 to $160 / 10005$. In our study $27.53 \%$ of them had no antenatal care (ANC); 55.06\% had unbalanced ANC or were attending the hospital for the first time after being talk about. Most of them came from low socioeconomic background. In our present study the majority of patients belong to age group of $20-30(67.42 \%)$ years. Several studies were done to see the risk factors of perinatal outcome of eclampsia and presented that eclampsia was found to be predominantly common in adolescent and young pregnant women. The finding is consistent with the study done by chowdhury $\mathrm{P}$, as the adolescent pregnancy constitutes a large number of hospital admission in obstetric unit and it may explain the higher no of cases of eclampsia in this age group. This cause of still birth may be due to late arrival of patients after onset of fits result in severe intrauterine hypoxia and intrauterine death. This may reveal lack of public awareness, lack of antenatal checkup ignored position of female in the family poor decision making facility of female, poor communication system and demerits of conservative method in patient management. Sources of early neonatal death may be as a result of high rate of eclampsia in preterm pregnancy affecting high preterm delivery and high perinatal loss. Other causes may be influenced by the availability and skills of neonatal care facilities in hospitals.

\section{Limitations of THE STUdy}

This was a single centered study with a small sized sample. So the findings of this study may not reflect the exact scenario of the whole country. 


\section{CONCLUSION AND}

\section{RECOMMENDATIONS}

It is known that social and economic determinants are associated with higher maternal and perinatal mortality. Our findings also show that lower income families have a worse performance in all obstetric health care indicators among women with eclampsia. Improving health systems is a must to reduce morbidity and deaths in women of reproductive age and their offspring. Proper health care and mental health facilities in order to get better obstetric and perinatal outcomes might be the faster route to reduce severe maternal outcome due to eclampsia. Succeeding emergency obstetric health care by encouraging continued staff training and growing the number of well-equipped health care facilities are a more acceptable and expedient way not only for women in Bangladesh, but also emerging nations who endeavor to relieve the burden of eclampsia.

\section{REFERENCES}

1. Report of the National High Blood Pressure Education Program Working Group on High Blood Pressure in Pregnancy. American Journal of Obstetris and Gynecology. 2000; 183(1): S1-S22.

2. Duley L. The global impact of pre-eclampsia and eclampsia. Seminars in Perinatology.20009; 33(3): $130-7$.

3. Khan KS, Wojdyla D, Say L, Gu“lmezoglu AM, Van Look PF. WHO analysis of causes of maternal death: a systematic review. Lancet.2006; 367(9516): 1066-74.

4. Fong A, Chau CT, Pan D, Ogunyemi DA. Clinical morbidities, trends, and demographics of eclampsia: a population-based study. American journal of obstetrics and gynecology. 2013 Sep 1;209(3):229-e1.

5. Arias F, Bhide AG, Arulkumaran S, Damania K, Daftary SN, editors. Practical Guide to High Risk Pregnancy and Delivery-E-Book. Elsevier health sciences; 2012 May 14.

6. Abalos E, Cuesta C, Grosso AL, Chou D, Say L. Global and regional estimates of preeclampsia and eclampsia: a systematic review. European Journal of Obstetrics \& Gynecology and Reproductive Biology. 2013 Sep 1;170(1):1-7.

7. Souza JP, Cecatti JG, Parpinelli MA, Sousa MH, Lago TG, Pacagnella RC, Camargo RS. Maternal morbidity and near miss in the community: findings from the 2006 Brazilian demographic health survey. BJOG: An International Journal of Obstetrics \& Gynaecology. 2010 Dec;117(13):1586-92.

8. World Health Organization. Global Program to Conquer Preeclampsia/ Eclampsia. 2002.

9. World Health Organization. WHO recommendations for prevention and treatment of pre-eclampsia and eclampsia. 2011.

10. Sontakke P, Reshmi RS, Sebastian D. Obstetric morbidity among currently married women in selected states of India. J Fam Welf. 2009;55: 17-26.

11. Ventura SJ, Martin JA, Curtin SC, Mathews TJ. Report of final natality statistics, 1996. Monthly vital statistics report. 1998 Jun 30; 46(11):10-49.

12. Douglas KA, Redman CWG. Eclampsia in the United Kingdom. BMJ. 1994; 309:1395-1400.

13. Sarika Chaturvedi, Bharat Randive, and Nerges Mistry, Availability of Treatment for Eclampsia in Public Health Institutions in Maharashtra, India J Health Popul Nutr. 2013 March; 31(1): 86-95.

14. Rao KB. Perinatal mortality. In: Ratnam SS, Rao $\mathrm{KB}$, Kumaran SA. Obsterics and gyanaecology for postgraduates. 2, 1st ed. Chennai: Orient Longman Ltd. 1997; 20: 252-9.

15. Robson SC. Hypertensiona and renal disease in pregnancy. In: Edmonds DK, editor. Dewhurst's text book of obstetrics and gynaecology for postgraduates. 6th ed. London: Blackwell Science Lt. 1999: 166-77.

16. Datta DC. Textbook of obstetric including perinatilogy and contraception. 4th ed. Calcutta. 1998; 51, 51, 236-9, 648-9.

17. Robson SC. Hypertensiona and renal disease in pregnancy. In: Edmonds DK, editor. Dewhurst's text book of obstetrics and gynaecology for postgraduates. 6th ed. London: Blackwell Science Lt. 1999: 166-77. 